\title{
POPULISMO E FAKE NEWS NA ERA DA PÓS-VERDADE: COMPARAÇÕES ENTRE ESTADOS UNIDOS, HUNGRIA E BRASIL
}

\author{
Ana Julia Bonzanini Bernardi ${ }^{1}$ \\ Andressa Liegi Vieira Costa ${ }^{2}$
}

RESUMO: Nas últimas eleiçôes, figuras populistas de extrema direita emergiram ou se fortaleceram em todo o mundo. Sabidamente, nem todos os governos populistas são iguais. Neste artigo procuramos investigar a cultura política e o uso de fake news nas campanhas/governos desses líderes populistas no Brasil, nos EUA e na Hungria. Primeiramente, discutimos o histórico político de cada país, bem como o perfil de seus governantes e o uso de fake news. Em seguida, aliamos a opiniáo pública e a cultura política da população presentes nos dois últimos anos eleitorais em cada país. Na terceira e última parte, fazemos comparações entre esses três países, observando mudanças no cenário político digital a partir dos índices do V-Dem Institute (Varieties of Democracy) de 2019.

PALAVRAS-CHAVE: Populismo. Pós-verdade. Opinião pública. Eleiçóes. Fake news.

\section{POPULISM AND FAKE NEWS IN A POST TRUTH ERA: COMPARISONS BETWEEN UNITED STATES, HUNGARY AND BRAZIL}

ABSTRACT: In the latest elections many populists' figures and right-wing extremists got elected or became stronger worldwide. It is well known that crises facilitate the concentration and abuse of power, once citizens are more likely to tolerate and support authoritarian

\footnotetext{
1 Universidade Federal do Rio Grande do Sul (UFRGS), Porto Alegre - RS - Brasil. Doutoranda no Programa de Pós-Graduação de Ciência Política. Orcid: https://orcid.org/0000-0001-7768-6264. anajuliabbernardi@hotmail.com.

2 Universidade de Lisboa, Instituto Superior de Ciências Sociais e Políticas, Lisboa - Portugal. Mestre em Ciência Política. Orcid: https://orcid.org/0000-0002-3655-1387. andressaliegi@hotmail.com.
} 
measures. It is known that not all populist governments are the same, in this paper we seek to investigate the public opinion and the political culture of each population that elected those populist leaders in Brazil, the USA and Hungary. First, we discuss the political background of each country, as well as the profile of the leaders and their usage of fake news during the campaign. Second, we assess public opinion, political culture of the population for the last two electoral years in each country. In the third and last part, we draw comparisons between these three countries observing changes in the digital political scenario, based on the indexes of the V-Dem Institute (Varieties of Democracy) 2019.

KEYWORDS: Populism. Post-truth. Public opinion. Elections. Fake news.

\section{A "nova onda" de governos populistas}

A eleição de candidatos que basearam suas campanhas e propostas em uma visão de governo para as pessoas reais e contra a elite no governo, vem sendo apontada como uma característica da nova onda de governos populistas. Contudo, algumas características desses governos vêm se mostrando claramente danosas para a democracia, principalmente no que tange o entendimento de quem são as "pessoas reais" e quais são as "elites do governo" (MÜLLER, 2017). Conforme apontado por Levitsky e Ziblatt (2018), a estabilidade das democracias tem se pautado muito pelo apoio das elites e partidos conservadores, que muitas vezes optaram por apoiar governos autoritários como uma forma de garantir benefícios econômicos (LEVITSKY; ZIBLATT, 2018). Nesse sentido, segundo Müller, o novo populismo precisa ser entendido mais como uma estratégia de esvaziamento da voz da oposição e uma radicalização de discurso autoritário e segregacionista (STANLEY, 2018) e menos como uma política contra as elites.

Assim, este artigo busca analisar o contexto no qual se elegeram governos populistas nos Estados Unidos, na Hungria e no Brasil, avaliando variáveis comportamentais, de cultura política e de opiniâo pública nesses países, ressaltando traços comuns, tais como o desinteresse e baixa satisfação pela política, a desconfiança generalizada, a insatisfação com o governo e a situação econômica e a percepção de polarização política. Em face de uma das características do populismo ser a centralização da persona do líder, este trabalho também dá ênfase ao comportamento dos eleitos em cada um dos países, nomeadamente Donald Trump (PR), Viktor Orbán (FIDeSz) e Jair Bolsonaro (PSL) e o uso de fake news durante e após as campanhas. Assim, avaliamos a narrativa do uso de discurso de um inimigo comum, a deslegitimação da oposição, a repressão da 
mídia e o uso de redes sociais e fake news como instrumentos de comunicação com o eleitorado, e posteriormente, com os cidadáos.

Para a realização desta pesquisa, consultamos bancos de dados de opinião pública de cada uma das regiôes, bem como fizemos revisão bibliográfica de literatura especializada. Além disso, utilizamos variáveis do Instituto V-Dem (Varieties of Democracy) para observar as mudanças no cenário político digital de cada país. Após as análises realizadas, indicamos haver uma consonância de contextos que possibilitaram a eleição desses líderes, sobretudo no que tange à desconfiança na política e insatisfação generalizada com o sistema político. Ademais, destaca-se o crescente uso de redes sociais, fake news e discurso de ódio por partidos políticos. Contudo, advoga-se que se faz necessário levar em conta questóes pertinentes à formação histórica de cada um dos países, bem como suas variáveis societais e demográficas para que se tenha uma análise mais acertada.

\section{Cenário de crescimento do populismo mundial}

A representação política tem sofrido transformações, dentre elas a perda de centralidade dos partidos políticos como organizadores das preferências e identidades eleitorais, além de sua função como agentes de integração social e instrumentos de diferenciação social e política, a partir da ruptura dos tradicionais vínculos entre os partidos e a sociedade civil. $\mathrm{O}$ aumento da descrença e desafeto dos indivíduos em relação às instituiçóes políticas, quando ainda somados a condiçóes econômicas precárias, produzem um ambiente político instável. Nesse cenário, vê-se um aumento nas mobilizaçóes populistas anti-establishment, com a ascensão de figuras políticas acima das estruturas partidárias, personificando a vontade social (LAVALLE; HOUTZAGER; CASTELO, 2006; BAQUERO; LINHARES, 2011; ROBERTS, 2019).

Algumas características da nova direita emergente no cenário mundial são o discurso antipluralista de combate a questóes identitárias; o uso de fake news com a exploração da pós-verdade e combate ao conhecimento científico; o posicionamento anti-establishment como outsiders por meio de narrativas antipolíticas de deslegitimação das instituições; a legitimação do discurso de ódio como liberdade de expressão; a utilização de redes sociais como canais de comunicação e proximidade com a população; uma aproximação com as classes médias e populares (os "perdedores da globalização"); em um discurso meritocrático e individualista (GALLEGO, 2019). A desigualdade econômica é um dos fatores geradores de insatisfação e fomentadores de discursos populistas, porém a ascensão dessas figuras apresenta também relação com um efeito de 
backlash cultural, ou seja, uma rejeição à emergência de valores progressistas por camadas que se ressentem do deslocamento das normas familiares tradicionais, e se colocam suscetíveis a apoiar discursos populistas (NORRIS; INGLEHART, 2019). A insatisfação com a realidade do país, a proliferação da desinformação e o acirramento dos discursos políticos, dentro de um contexto de pós-verdade, são terreno fértil para a eleição de líderes populistas.

Sobre o contexto da desinformação, duas expressóes em inglês são muito utilizadas para falar da onda de fake news atual, sendo elas misinformation e desinformation. A primeira trata de informaçóes falsas ou imprecisas espalhadas de forma não intencional - como, por exemplo, um erro de reportagem. Já desinformation, em português desinformação, delimita aquela estratégia em que o conteúdo é intencionalmente falso e deliberadamente propagado para enganar usuários e se multiplicar pelas redes (ALLCOTT; GENTZKOW, 2017; CASTRO, 2018; EUROPEAN COMISSION, 2018; MARWICK; LEWIS, 2017). Nesse sentido, fake news são narrativas difundidas intencionalmente, passíveis de serem verificadas como fraudulentas e com a única intenção de enganar os interlocutores (SHU et al., 2017). Assim:

Tal definição exclui erros jornalísticos não intencionais; rumores, ou seja, informaçôes que não são verificadas no momento da postagem (ZUBIAGA et al., 2018); teorias de conspiração, entendidas como explicaçóes sobre eventos históricos em termos do agente causal de um grupo relativamente pequeno de pessoas agindo em segredo (KEELEY,1999); sátiras, que são facilmente identificáveis pela característica de entretenimento; fofocas, que são afirmaçôes não validadas e não consentidas sobre pessoas ou fatos, e declaraçôes falsas (CASTRO, 2018, p. 64).

O Dicionário Oxford definiu o termo pós-verdade como a palavra do ano de 2016, pós-eleiçóes de Trump nos Estados Unidos, o que reacendeu os estudos do impacto das fake news na democracia eleitoral. Assim, caracterizou a pós-verdade como "relativa a circunstâncias em que fatos objetivos são menos influentes na formação da opinião pública do que emoções e crenças pessoais ${ }^{3 "}$ " (OXFORD LANGUAGES, 2016, tradução nossa). O fenômeno da pós-verdade e das fake news está intrinsecamente ligado a uma refutação da ciência e uma aceitação de discursos inflamados por preconceitos, intolerâncias e táticas de uso de caos e

3 "Post-truth is an adjective defined as 'relating to or denoting circumstances in which objective facts are less influential in shaping public opinion than appeals to emotion and personal belief"' (OXFORD LANGUAGES, 2016). 
confusão como forma de manipulação da sociedade civil e da opinião pública, lançando mão de manobras populistas e extremistas (KAKUTANI, 2018).

Embora as fake news, em pleitos eleitorais, sejam utilizadas por diferentes partidos do espectro direita-esquerda, o conceito tem encontrado mais legitimidade entre os candidatos populistas de direita (D'ANCONA, 2018). Bem como Donald Trump, nos EUA; Marine Le Pen, na França; Viktor Orbán, na Hungria; e Jair Bolsonaro, no Brasil, utilizam-se de discursos de ódio a seus "oponentes ilegítimos” (APPLEBAUM, 2017). Os líderes populistas se aproveitam desse contexto para legitimar seu comportamento autoritário, ganhando apoio da populaçáo. Nas próximas seçóes, analisaremos as especificidades em cada país, avaliando o contexto da eleição de cada um dos líderes.

\section{Estados Unidos e a cooptação do termo fake news por Trump}

Existem muitos estudos que atribuem a vitória de Donald Trump, em 2016, às questóes econômicas e às falhas do Governo Obama, principalmente em responder aos setores mais conservadores do país. De acordo com pesquisa do Latin American Public Opinion Project (LAPOP, 2017), apenas metade da população estadunidense se mostrava satisfeita com a democracia entre os anos de 2016 e 2017, muitos citando o mau governo (27\%) e a corrupção (11\%) como principais problemas do país.

Além da baixa econômica causada pelo avanço chinês, as primárias de 2016 foram marcadas pelo vazamento de e-mails de Hillary Clinton e um forte antagonismo entre a candidata e Bernie Sanders, o que enfraqueceu a candidatura democrata. Ao mesmo tempo, a estratégia de campanha de Donald Trump de estar sempre presente nas mídias, sendo polêmico ou se utilizando de notícias falsas, aproveitando-se de sua alta capilaridade nas redes sociais, promoveu forte engajamento para o candidato republicano. Além disso, ainda não é claro o quanto o trabalho da Cambridge Analytics e a possível interferência russa podem ter influenciado o resultado dessas eleiçóes.

$\mathrm{Na}$ esteira desse debate, atualmente, quase três anos após as eleiçôes de 2016, a discussáo sobre o impacto das fake news segue recente e especialistas ainda apontam a eleição norte-americana de 2016 como um dos estopins do uso de fake news em processos eleitorais. Donald Trump promoveu a popularização do termo fake news como uma forma de se opor às notícias divulgadas pela mídia tradicional. Assim, desde 2015, vem fazendo uso de suas redes sociais, principalmente o Twitter, em oposição à imprensa, para declarar que diferentes notícias danosas à sua campanha, ou pessoa, tratavam-se de fake news. De acordo 
com o site Trump Twitter Archive, desde que a sua conta foi inaugurada, Trump já utilizou o termo fake news em 647 tweets $^{4}$, na maioria deles se referindo a veículos de mídia tradicional, tais como The New York Times e The Washington Post.

Nesse sentido, podemos observar os dados de confiança nas instituiçóes em pesquisa do Lapop de 2016/17 na tabela, abaixo, em que 55,3\% das pessoas consultadas afirmam não confiar na mídia.

Quadro 1 - Confiança nas instituiçóes - EUA (\%)

\begin{tabular}{|l|c|c|c|}
\hline & Não confia & Mais ou menos & Confia \\
\hline Partidos políticos & 68,2 & 19,1 & 12,85 \\
\hline Forças armadas & 13,5 & 12,2 & 74,2 \\
\hline Congresso & 22,7 & 18,7 & 22,4 \\
\hline Governo Nacional/ Executivo & 44,9 & 10,6 & 31,8 \\
\hline Mídia & 55,3 & 17,2 & 27,5 \\
\hline Eleiçốes & 33,1 & 17,5 & 49,4 \\
\hline
\end{tabular}

Fonte: Elaboração própria através de Lapop (2017), $\mathrm{n}=1500$.

Ao longo de toda a campanha em 2016, não apenas postagens e links de páginas apoiadoras de Trump foram identificados divulgando notícias falsas, como o próprio Trump se utilizou de diversas notícias falsas em seus posts e posicionamentos públicos. Assumindo em 2017 como presidente, seguiu utilizando discursos fraudulentos ou, no mínimo, exagerados, em seus tweets e entrevistas. Segundo levantamento do Fact Checker, agência ligada ao jornal The Washington Post, ao longo das eleiçóes de 2016, Trump proferiu pelo menos 92 falas consideradas falsas (a maioria, completamente falsa), mais que o dobro de Hillary Clinton (THE 2016 ELECTION..., 2016). De acordo com levantamento do Comitê de jornalistas livres dos Estado Unidos, entre o anúncio de sua candidatura, em 2016, até o final do seu segundo ano como presidente, cerca de $11 \%$ do total de tweets escritos pelo presidente tinham um cunho de ameaça, condenação ou insulto a jornalistas, jornais específicos ou à mídia, de maneira geral (SUGARS, 2019). Nesse sentido, o uso das redes sociais para se comunicar com seus apoiadores mostra-se instrumental para Trump, já que, segundo Ituassu et al. (2018) a rede social permite a comunicação direta com seus apoiadores sem o filtro dos jornalistas, tradicionais gatekeepers da democracia (OATES; MOE, 2016). No ambiente de redes sociais, as

4 Até 02/04/2020. Disponível em: http://www.trumptwitterarchive.com. Acesso em: 02 abr. 2020. 
informações falsas são multiplicadas pelos robôs, impulsionando postagens de forma artificial (ITUASSU et al., 2018).

De forma geral, o "Relatório de Notícias Digitais" do Instituto Reuters (NEWMANN et al., 2019) revela essa tendência de diminuição de confiança na mídia tradicional nos Estados Unidos. A forma de informação mais utilizada é a online seguindo uma tendência anterior, o que inclui as redes sociais; porém, é interessante observar que, mesmo se mantendo à frente de outros suportes, esse tipo de veiculação de dados e notícias também sofreu uma redução considerável nos últimos anos. Em 2017, 77\% dos respondentes utilizavam a internet para se informar. Atualmente, essa parcela ficou em $73 \%$. O uso de fonte de informaçóes de redes sociais, de maneira isolada, em 2017 representava os hábitos de 47\% dos consultados. Em 2018, o percentual diminuiu para 45\%. Dentre os níveis de confiança em notícias, houve uma queda de $4 \%$ na avaliação dos que participaram da enquete, respondendo por apenas 34\% do universo da pesquisa em 2018. Ainda no que tange à confiança em notícias, aqueles que afirmaram confiar, isoladamente, nas redes sociais como fonte de informação eram, em 2018, apenas 13\% do total (NEWMANN et al., 2019).

Em ambiente polarizado, ainda mais considerando a estrutura de presidencialismo bipartidária nos Estados Unidos, a estratégia republicana conseguiu capturar votos com slogans populistas e fáceis, em um contexto de crise econômica global, ascensão da China, tendo como mote a ideia do Make America Great Again. Entrando na política como um empresário de grande sucesso, em um ambiente em que a política e a mídia estavam desacreditadas, Trump, ao levantar inúmeras controvérsias, fosse com as notícias falsas que enunciava, ou com seu discurso preconceituoso, machista e xenofóbico, conseguiu capturar a velha mídia com coberturas gratuitas de suas posiçóes polêmicas, mostrando-se um candidato com qualidades especificamente interessantes para a era digital (LEVITSKY; ZIBLATT, 2018).

Em estudo sobre os Estados Unidos nas eleiçóes de 2016, Allcott e Gentzkow destacaram alguns achados sobre as redes sociais e o consumo de fake news nas eleiçôes de Trump, tais quais: 1) cerca de 62\% de adultos norte-americanos recebem notícias nas redes sociais; 2) muitas pessoas que leem notícias falsas relatam acreditar nelas; e, por fim, 3) as notícias falsas mais discutidas durante as eleiçôes favoreciam Donald Trump em relação à Hillary Clinton (ALLCOTT; GENTZKOW, 2017).

Das fake news de fonte não identificada, segundo o estudo de Silverman (2016), entre as 20 histórias que geraram maior engajamento (incluindo curtidas, compartilhamentos e comentários) nos três meses antes das eleiçóes, dezes- 
sete eram abertamente pró-Donald Trump ou anti-Hillary Clinton. A que teve maior alcance foi o "Papa Francisco choca o mundo e apoia Donald Trump" que atingiu quase mais de 900.000 engajamentos no Facebook. A segunda delas constava que Wikileaks havia confirmado que Hillary Clinton havia vendido armas para o Estado Islâmico com 789.000 de engajamentos no Facebook (SILVERMAN, 2016).

\section{A democracia iliberal húngara de Viktor Orbán}

Desde o começo do seu mandato em abril de 2010, o Governo de Viktor Orbán (FIDeSz) iniciou diversas modificações na Constituição e nas Leis Eleitorais ${ }^{5}$ do país que levantaram questionamentos de até que ponto estas mudanças não representavam uma afronta à democracia e independência das instituiçôes, indicando a formação de um Estado autoritário, com poder centralizado nas mãos do Primeiro Ministro (MULLER, 2017). Segundo críticas internacionais, as ementas feitas à Constituição violavam os tratados de direitos humanos da ONU e do Conselho Europeu, assim como entravam em desacordo com os princípios básicos da União Europeia, que requisitam a existência de instituiçôes independentes funcionando em um sistema de balanceamento dos poderes, garantindo as liberdades individuais de toda a população (NORWEGIAN HELSINKI COMMITTEE, 2013 p. 8), assemelhando-se, o sistema político do país, a uma autocracia, ou a uma democracia iliberal (VEGETTI, 2018; LEVITSKY; ZIBLATT, 2018).

A Hungria tem um sistema eleitoral altamente complexo, com distribuição desproporcional. A nova lei, que regulou as eleiçôes de 2014 e de 2018, aumentou a percentagem de assentos parlamentares eleitos em distritos uninominais, tornando o sistema ainda mais desproporcional. Em segundo lugar, mudou os limites dos distritos eleitorais para a vantagem do FIDeSz, rendendo a reeleição de Orbán, em 2014 e em 2018, com 43,7\% e 48\% dos votos, respectivamente

\footnotetext{
5 A nova Lei Eleitoral se nomeia "Ato das Eleições de Membros do Parlamento da Hungria”, sendo descrita em 26 artigos que determinam os parâmetros da distribuição de assentos e do processo de votos, bem como dos direitos e deveres dos candidatos e tudo que envolve o processo eleitoral. Primeiramente, o número de parlamentares passou de 386 para 199; também faz uso somente de dois mecanismos para a eleição e não de três. No novo sistema, existem somente duas fases nas eleições: 106 assentos são preenchidos nas eleições por circunscrição de candidato único (que elege um membro por circunscrição). Noventa e três são eleitos por meio das listas nacionais dos partidos. Obrigatoriamente, as 176 circunscrições eleitorais húngaras existentes passaram a ser somente 106, concentrando um número máximo de cerca de 76.000 votos por circunscrição. Acrescido a isso, os votos de candidato único por circunscrição distrital ocorrem em somente um turno, usando pluralidade simples. No entanto, o eleitor ainda tem dois votos: um para o candidato único por circunscrição e outro para a lista nacional do partido (RENWICK, 2011).
} 
(VEGGETI, 2018; RENWICK, 2011). Fora o sistema eleitoral desproporcional, também houve alegaçóes não comprovadas de fraude nessa corrida eleitoral que se desdobrou um ambiente de fortes restriçóes à liberdade de expressão: fechamento de organizaçóes civis, de agências de jornalismo opositoras ao governo e restrição à liberdade de cátedra das instituiçôes científicas (ASH, 2019). Segundo observadores da OSCE, a corrida eleitoral se deu em "[...] espaço limitado para debates substantivos e diminuição da capacidade dos eleitores de fazer uma escolha informada, onde a mídia pública claramente favoreceu a coalizão vencedora” (JUHÁSZ, 2018).

Atualmente, a Hungria está entre as democracias com os mais baixos índices de liberdade de imprensa (LUHRMANN et al, 2019), e diferentemente do Brasil e dos Estados Unidos, a maior parte dos veículos de imprensa pertence, ou é vinculada ao governo central (KREKÓ et al., 2018; NEWMANN et al., 2019). A gestáo Orbán fez uso de uma agressiva campanha anti-imigração e contra a União Europeia, colocando jornalistas críticos ao governo, Bruxelas, imigrantes e a comunidade científica, como inimigos da nação húngara. Fazendo uso da narrativa de que seriam fake news todas as informaçóes contrárias ao governo, Orbán espalhou outdoors pelo país com a frase: "Você tem direito de saber o que Bruxelas planeja”, indicando que a Uniâo Europeia estaria agindo contra os interesses do país na questão dos refugiados. Também promoveu uma perseguição às instituiçôes de ensino e ONGs ligadas a George Soros, indicando que haveria uma conexão entre o empresário e a promoção de terrorismo, o qual chamou de "Plano Soros"6.

A presença do elemento autoritário e repressor foi uma constante na história húngara, tanto nas ocupaçóes turcas (1526), nazistas (1944-1947), e soviéticas (1947-1989), quanto nos regimes internos caracterizados pela República Socialista de Khun (1917), Era Horthy e controle nazista húngaro (19201944) - de forma que grande parte da população húngara não viveu de fato uma democracia. Com a reabertura política em 1989, o país voltou a se inserir no sistema internacional, buscando um maior contato com o Ocidente para se integrar à União Europeia. A transição democrática e a reforma do sistema eleitoral se deram como um pacto entre as elites políticas do país, uma vez que a população, doutrinada pelos tantos anos de regimes autoritários, não mani-

\footnotetext{
6 Em 27 de abril de 2017, a Comissão salientou que o processo de consulta nacional "Vamos parar Bruxelas" continha várias alegações factualmente incorretas ou altamente enganadoras. O Governo húngaro realizou ainda consultas intituladas "A imigração e o terrorismo", em maio de 2015, e contra um suposto "Plano Soros", em outubro de 2017. Essas consultas estabeleceram um paralelismo entre o terrorismo e a migração, incitando o ódio contra os migrantes e, em especial, à pessoa de George Soros e à União. (SARGENTINI, 2018, p.9).
} 
festou interesse ou tomou parte nas discussóes (LENGYEL; ILONSZKI, 2012; KOROSENY, 1999).

Nesse sentido, o populismo no leste europeu, mostra-se diferente do populismo norte americano, justamente pelo caráter iliberal (KREKÓ et al., 2018; SIERAKOWSKI, 2018). Na Hungria, não há uma salvaguarda de checks and balances por parte das instituiçôes, de forma que Viktor Orbán vem modificando a constituição com vistas a melhor servir o seu partido, FIDeSz, no poder desde 2010. A cultura política de não participação da sociedade civil, herança dos anos autoritários, torna mais difícil a adoção e preocupação da sociedade com valores de pós-materialistas e de autoexpressão (INGLEHART, 2018), fazendo com que a liberdade de expressão e o judiciário independente sejam alvos fáceis de ataques pelos governos de direita populista da região.

De acordo com Sierakowski (2018), o populismo húngaro vai além da premissa de eleitores frustrados, economicamente, e encontra adesão da classe trabalhadora pela construção de um senso de comunidade, e na classe média por se destacar como diferente dos refugiados e das elites cosmopolitas. Para Krekó et al. (2018), o sucesso dos líderes populistas da direita na região se dá, pois estes exploram os medos da população. Utiliza o termo tribalismo para conceituar o sentimento de busca por uma identificação nacionalista, pois usa o peso de nação e não de classe - atuando sobre a identidade e não sobre o bem-estar econômico. Além disso, o partido construiu um grupo de populismo de direita que combina sucesso econômico, valores familiares (ter filhos traz muitos benefícios) e devoção religiosa, criando o ideal de uma cultura "cristã-nacional" (MULLER, 2017).

Essas afirmaçóes vão de encontro à cultura política húngara. Segundo o European Social Survey, em 2017, quase 70\% dos húngaros afirmaram ter nenhum/pouco interesse sobre política, e apenas 5,3\% afirmaram ter muito interesse. Nesse mesmo sentido, apenas 27\% dos respondentes afirmaram que o sistema político húngaro permite que as pessoas tenham alguma participação no governo. O baixo interesse por política tende a crescer dentro de ambientes polarizados e reverbera em forma de desconfiança nas instituições e pessoas. Os baixos níveis de confiança são recorrentes na história húngara. Números de 2017, cenário pré-eleitoral, esclarecem que se trata de um quadro generalizado. 
Quadro 2 - Confiança nas instituiçóes - Hungria (\%)

\begin{tabular}{|l|c|c|c|}
\hline & Não confia & Confia & Neutro \\
\hline Partidos políticos & 61,6 & 21,1 & 13,1 \\
\hline Polícia & 19,1 & 65,5 & 6,1 \\
\hline Parlamento Nacional & 43,4 & 35,0 & 18,6 \\
\hline Políticos & 57,1 & 25,1 & 11,7 \\
\hline Mídia* & 46,3 & 50,8 & 2,8 \\
\hline
\end{tabular}

Fonte: European Social Survey, Onda 9, 2018. N = 15987.

${ }^{*}$ Eurobarometer $90.3 \mathrm{~N}=1023^{8}$.

Sob os apontamentos na definição de capital social feitas por Almond e Verba, (1963), reitera-se que outro aspecto importante para uma cultura política democrática é que a sociedade tenha um alto nível de confiança nas instituiçóes que regem seu país, para que se mantenham, de fato, níveis de civilidade e de respeito mútuo. $\mathrm{O}$ fato de a instituição com maior confiança ser a polícia, demonstra o quão malvistas são as instituiçóes húngaras. O populismo, geralmente, encontra ambiente fértil em sociedades com alta polarização e desconfiança, nas quais um líder carismático busca apontar um inimigo comum como forma de criar identificação de um grupo. Não diferentemente, em pesquisa realizada pelo Ipsos, em janeiro de 2018, pouco antes das eleições, $86 \%$ dos húngaros afirmaram acreditar que a população estava dividida e apenas $16 \%$ avaliavam que havia muita/alguma tolerância com os que pensavam de forma diferente, sendo $50 \%$ dessas diferenças de origem política (ATKINSONS; SKINNER, 2018).

Dentro desse quadro, percebe-se que a satisfação com a democracia no país também é muito baixa, uma vez que quase metade dos húngaros afirma estar muito insatisfeita com a democracia no país. Em 2018, um mês antes das eleições de Orbán, em pesquisa do Ipsos, 58\% da população húngara apontava como principal problema do país a corrupçáo política e financeira (ATKINSONS; SKINNER, 2018). Complementarmente, pesquisa realizada em junho de 2018 pelo Ipsos, encontrou que $73 \%$ da população húngara afirmava que os políticos

\footnotetext{
Disponível em: https://www.europeansocialsurvey.org/download.html?file=ESS9HU\&c=HU\&y=2018. Acesso em: 24 ago. 2020.

8 Disponível em: https://ec.europa.eu/commfrontoffice/publicopinionmobile/index.cfm/Survey/getSurveyDetail/ surveyKy/2215. Acesso em: 24 ago. 2020.
} 
deveriam poder falar o que pensam, independentemente de quem pudesse se sentir ofendido com isso. Cerca de $47 \%$ afirmaram que o país precisava de um líder firme que estivesse disposto a quebrar as regras. No mesmo sentido, 85\% dos húngaros afirmaram não confiar na mídia.

\section{Bolsonaro e a nova (velha) política}

O Brasil tem apresentado altos níveis de desconfiança em relação ao governo e seus representantes, assim como grande ceticismo político entre a população (BAQUERO, 2004, 2008). Somado a isso, a existência de forças oligárquicas na democracia brasileira reforça a exclusão e a desigualdade sociais, uma vez que favorece minorias no poder e, consequentemente, elites políticas dos partidos políticos centrais acabam por ser vistas como corruptas e preocupadas apenas com seus próprios interesses, em detrimento do bem do país, acentuando a descrença nas instituiçôes (BAQUERO, 2004). A difusão de um sentimento de antipolítico também aumenta o descrédito nas instituiçôes, sendo igualmente reforçado pela mídia (BAQUERO; RANINCHESKI; CASTRO, 2018).

A campanha eleitoral brasileira de 2018, embora tenha sido encurtada pela legislação de 2017 e iniciada oficialmente em 16 de agosto de 2018 (Lei $\mathrm{n}^{\circ} 13.487 / 17$ e Lei no $\left.13.488 / 17\right)$, começou muito antes nas redes sociais e nas manifestaçóes de 2013 (GALLEGO, 2019). O período foi marcado por um impeachment, até hoje questionado e chamado de golpe, e diversas manifestações pró e contra o governo, nas quais "novas e velhas" candidaturas foram se formando - como a de Jair Bolsonaro - mesmo que ainda náo oficialmente (GALLEGO, 2019). Novas, pois houve a maior taxa de renovação do Congresso desde 1994, mas "velhas" pois reelegeu candidatos com acusaçóes de corrupçáo, também a bancada mais conservadora eleita desde o regime militar em 1964 tendência que já havia se mostrado presente em 2014 (ABRANCHES, 2019). As redes sociais foram marcadas pela ação dos bots sociais e de criação de notícias falsas, que cresceram de forma profícua no período, alavancadas em momentos chaves e de condenação da Operação Lava-Jato (ARNAUDO, 2017; FACHIN; MACHADO, 2018). 
Quadro 3 - Confiança nas instituiçóes - Brasil (\%)

\begin{tabular}{|l|c|c|c|}
\hline & Não confia & Mais ou menos & Confia \\
\hline Partidos políticos & 62,9 & 30,2 & 7,0 \\
\hline Forças Armadas & 13,8 & 33,8 & 52,4 \\
\hline Congresso & 39,3 & 43,5 & 17,2 \\
\hline Governo Nacional/ Executivo & 27,2 & 34,6 & 38,1 \\
\hline Mídia & 18,3 & 47,9 & 33,9 \\
\hline Eleiçóes & 36,8 & 44,2 & 19,0 \\
\hline
\end{tabular}

Fonte: Elaboração própria através de LAPOP (2019), N = 1479.

Os sentimentos que se desenvolveram, de desafeição e insatisfação com as instituiçóes, acentuados a partir dos protestos de 2013, seguidos pelas eleiçóes de 2014 que, com a ampla cobertura midiática da Operação Lava Jato e o processo de impeachment de Rousseff, resultaram no cenário que podemos observar no quadro acima (Quadro 3), em 2018/19. Primeiramente, aponta-se a baixíssima confiança nas instituiçóes políticas, especialmente nos partidos, nos quais mais de $60 \%$ dos cidadãos não confiam de forma alguma, seguidos pelo Executivo e pelo Legislativo, ambos apresentando desconfiança de uma parcela expressiva dos indivíduos. Em contraponto, as Forças Armadas contam com confiança de mais de $50 \%$ dos brasileiros. Com a rejeição à política tradicional, usando de discurso antipartidário, as Forças Armadas ganharam credibilidade no cenário público brasileiro. Ganharam muito espaço político no governo de Temer, o que foi reforçado pela retórica militarista de Bolsonaro (GALLEGO, 2019).

Como agravante, a corrupção é percebida como generalizada entre a sociedade brasileira, especialmente no que concerne ao Executivo e ao Legislativo, e resulta também em queda no apoio ao sistema político vigente no país (COSTA, 2018). Consequentemente, 17\% dos brasileiros entrevistados em 2018 apontam a corrupção como um dos maiores problemas do país (LAPOP, 2019), percepção que sofreu grande aumento em razão da forte cobertura midiática da Operação Lava Jato (BAPTISTA, 2017). O problema se acentua quando observada a percepção da sociedade sobre outros outputs do sistema político. Em 2018, 18,5\% dos brasileiros mencionaram o desemprego, e 7,3\% a economia, como os maiores problemas do país (LAPOP, 2019) e "quando o desafeto das pessoas em relação às instituiçóes de mediação política é elevado, a situação tende a piorar se as condiçóes econômicas também são precárias, produzindo um ambiente político instável” (BAQUERO; LINHARES, 2011). Além disso, a desigualdade e insegurança econômica são 
outros fatores relacionados ao apoio de líderes populistas (INGLEHART; NORRIS, 2016).

Nas eleiçôes de 2018, Jair Bolsonaro, candidato de extrema direita, foi eleito, em segundo turno, com 55,13\% dos votos válidos, contra seu oponente, Fernando Haddad, do Partido dos Trabalhadores. Bolsonaro é um ex-militar e foi integrante do Congresso Nacional por 30 anos, tendo seus discursos pautados nas linhas centrais a rejeição aos direitos humanos (anti-LGBTs, racismo, contra liberdade de expressão), a apologia à ditadura e ao golpe militar, tortura e violência, o combate à corrupção, direito dos militares e militarização da sociedade. Como candidato, criticou a democracia brasileira baseado na corrupçáo e na ineficácia dos serviços públicos, além de acusaçóes de apoio do governo de então a líderes como Hugo Chávez e Fidel Castro (MAITINO, 2018). Teve como um dos eixos de sua campanha o movimento anticorrupção (BOADLE; STARGARTDER, 2018), criticando a democracia no país (MAITINO, 2018), culpando o sistema político como um todo pela situação brasileira (GALLEGO, 2019), apresentando-se por meio de uma figura carismática como a única alternativa de mudança para o país (SANTANA, 2017).

Além da corrupção, a temática da falta de segurança e da violência nas áreas urbanas eram pautas de grande interesse da sociedade, ao passo que $16,8 \% \mathrm{da}$ população brasileira considerava estes tópicos como principais problemas do país (LAPOP, 2019). Jair Bolsonaro apostou na temática da segurança pública como um dos focos de sua campanha, utilizando-se do slogan "bandido bom, é bandido morto", enquanto os partidos de esquerda negligenciaram as pautas de segurança pública em detrimento da defesa dos direitos humanos. O então candidato fazia gestos de arma durante toda a sua campanha, apostando em propostas de liberalização do porte de armas para a população (PINHEIRO-MACHADO; SCALCO, 2018). Assim, Bolsonaro conseguiu transformar a insatisfação, fruto da crise econômica e política reforçadas pelos escândalos de corrupção e sentimento de insegurança em potencial eleitoral (GALLEGO, 2019).

Em pesquisa realizada pelo Lapop em 2018/9, mais de 57\% dos entrevistados afirmaram estar insatisfeitos ou muito insatisfeitos com a democracia no país e apenas 7,5\% afirmaram estar muito satisfeitos (LAPOP, 2019). A desconfiança em relação à política se mostra como uma forte marca da população brasileira, da qual 44\% afirmaram estar pessimistas com o resultado das eleiçóes de 2018 em pesquisa da CNI realizada em 2017. Os motivos mais citados nas respostas espontâneas foram a corrupção (30\%), a falta de confiança no governo (19\%) e a falta de opções (16\%) entre os pré-candidatos à presidência (BERNARDI, 2019). 
Assim como Donald Trump, Bolsonaro teve forte uso das redes sociais, especialmente do aplicativo de mensagens WhatsApp, uma plataforma que conta com cerca de 120 milhóes de usuários no Brasil. Seus seguidores criaram centenas de grupos no aplicativo para compartilhar mensagens, imagens, vídeos e memes, disseminando conteúdos e informaçôes falsas sobre seus rivais políticos e minorias (BRANCHO-POLANCO, 2019). Ademais, na época do segundo turno, Bolsonaro tinha 1,6 milhão de seguidores no Twitter e 7,49 milhões no Facebook - em comparação, Haddad tinha 742 mil seguidores no Twitter e 808 mil no Facebook (BERNARDI, 2019). De acordo com a pesquisa eleitoral do Instituto Datafolha, conduzida em outubro de 2018, entre os que declararam intenção de voto para Bolsonaro (em cenário de segundo turno contra Haddad) $84,2 \%$ possuíam conta no Facebook, dos quais $81,8 \%$ utilizavam a plataforma para ler notícias de cunho político e $41,4 \%$ as compartilhavam. Já em relação ao aplicativo de mensagens WhatsApp, 98,4\% dos consultados eram usuários da tecnologia. Desse universo, 74,4\% utilizavam o app para ler notícias e 44,9\% faziam compartilhamentos por meio dele.

Assim, foi o candidato que mais se utilizou de suas próprias redes sociais para dialogar com seu eleitorado. Muitas vezes tendo embates com a mídia tradicional, o candidato ao longo da eleição, e depois de eleito, tem se utilizado fortemente do Twitter e de sua página oficial do Facebook para se comunicar com a população. Adotando a conotação de fake news utilizada por Trump, determinando críticas e notícias desfavoráveis às suas açóes como falsas, o candidato evita os gate keepers da mídia tradicional, a qual desqualifica como tendo viés ideológico esquerdista e, para evitar que seu discurso receba o filtro jornalístico, comunica-se diretamente com a população pelas redes sociais, pelo uso de lives, e pronunciamentos diários. A desqualificação dos veículos jornalísticos engloba desde a Rede Globo, até o The Economist, o The Guardian, a Folha de Sáo Paulo, entre outros. Em seu primeiro ano de governo, 2019, de acordo com a Federação Nacional de Jornalistas, houve um aumento de 54\% nas agressóes a jornalistas e a veículos de comunicação, sendo mais da metade dos ataques realizados por Bolsonaro (MEDEIROS, 2020).

\section{Ascensão populista, cultura política e opinião pública comparada: redes sociais e fake news}

Até agora, neste artigo, descrevemos as principais características de cada país, e o contexto no qual cada líder foi eleito, destacando acontecimentos e elementos sociais por trás de sua cultura política. Conforme observado, um dos 
elementos em comum entre os líderes estudados é a forte presença nas redes sociais e seus discursos em formato de apelo direto à população, frequentemente com ataques a grupos específicos. Nesta seção, compararemos os países usando índices do $\mathrm{V}$-Dem, analisando alguns aspectos referentes ao ambiente político e o uso de fake news na esfera digital.

A extrema direita emergente se utiliza da força simbólica, com a disputa de imaginários e subjetividade, por meio do uso de aspectos emocionais para se comunicar de forma afetiva (GALLEGO, 2019). Líderes populistas buscam uma conexão direta com o povo, tanto para estabelecer uma comunicação sem filtros ou interferência, quanto para se informar sobre seus problemas e opinióes. Sendo assim, as redes sociais oferecem um ambiente sem constrangimentos por parte da mídia tradicional, inclusive, muitas vezes sendo desafiadas pelos populistas por meio das plataformas digitais (AZEVEDO, 2019).

Segundo Kahnemann (2012) quando estamos diante de novas informaçôes, temos uma tendência a pensar intuitivamente, utilizando-nos de conhecimentos prévios. Da mesma forma, temos um realismo ingênuo (naive realism), que nos condiciona a acreditar que a nossa percepção do mundo é a mais correta, negando posiçóes contrárias. Demarca-se a característica do viés de confirmação (confirmation bias), que está relacionado a uma maior aceitação de visões de vida similares as nossas (MCCRIGHT; DUNLAP, 2017). Se essas características já são latentes em nossas relaçôes, nas redes sociais elas se tornam ainda mais marcantes, uma vez que os indivíduos tendem a se relacionar e compartilhar conteúdos com pessoas que tem ideologias semelhantes às suas (tanto pelos algoritmos, quanto por predisposiçóes pessoais), reforçando a autoestima e se mantendo em ambientes "socialmente seguros" (BERNARDI, 2019).

Nessa acepção, se formam as chamadas câmaras de eco (echo-chambers), ou bolhas de filtro (filter bubbles) nas redes sociais que, ao isolar indivíduos que compartilham crenças e pensamentos homogêneos dentro das mesmas frequências algorítmicas, facilitam a propagação de fake news, já que as mesmas notícias são visualizadas diversas vezes no mesmo ambiente, sendo recompartilhadas por pares que contam com credibilidade social. Em ambientes altamente polarizados e nos quais as principais instituições, sobretudo políticas e midiáticas, são desacreditadas, as pessoas têm a tendência a confiar muito mais em notícias compartilhadas por pessoas próximas, que reforçam as suas crenças em determinado assunto (RUEDIGER, 2018).

Nesse sentido, no quadro abaixo (Quadro 4), podemos verificar os índices de uso de redes sociais pelos partidos/candidatos nos três países: 
Quadro 4- Uso de redes sociais por partidos e candidatos

\begin{tabular}{|c|c|c|c|c|c|}
\hline \multicolumn{2}{|c|}{ Brasil } & \multicolumn{2}{c|}{ EUA } & \multicolumn{2}{c|}{ Hungria } \\
\hline $\mathbf{2 0 1 4}$ & $\mathbf{2 0 1 8}$ & $\mathbf{2 0 1 2}$ & $\mathbf{2 0 1 6}$ & $\mathbf{2 0 1 4}$ & $\mathbf{2 0 1 8}$ \\
\hline 1,93 & 2,95 & 2,9 & 2,99 & 2,94 & 2,94 \\
\hline
\end{tabular}

Fonte: Elaboração própria através de Lührmann et al. (2019) ${ }^{9}$.

Sendo 3 o valor máximo atribuído à frequência de uso de redes sociais por partidos políticos e candidatos, podemos verificar o crescimento mais notável no Brasil, que aumentou mais de uma unidade no índice no período. Embora nas eleiçóes de 2014 a memetificação da política nas redes já fosse presente (CHAGAS; SANTOS, 2018), as campanhas eleitorais do ano de 2018 se deram em um ambiente muito mais virtual, até pelo crescimento no acesso à internet no país (RUEDIGER, 2018; BERNARDI, 2019).

Embora notícias falsas na política não sejam um advento da internet, a sociedade de redes que ela proporciona, na qual cada usuário vira produtor/ reprodutor de conteúdo, potencializa a disseminação de informaçóes falsas, muitas vezes não na intenção de causar dano, mas pela própria ignorância por parte do usuário e vontade de ter sua opinião validada (CARNEIRO, 2018). Considerando a facilidade de se encontrar informaçóes no ambiente online e a multiplicidade de sites com checadores de fatos, percebemos que as fake news podem ser desmentidas com simples buscas na web (RUEDIGER, 2018), contudo, muitos partidos e candidatos se utilizam desta narrativa para convencer eleitores e fidelizar apoiadores (OWEN, 2017). Dentro desse contexto, podemos verificar o aumento da disseminação de informaçóes falsas nos países no Quadro 5 (abaixo).

\footnotetext{
9 * 0: Nenhum: Principais partidos políticos e candidatos não usam a mídia social durante as campanhas eleitorais para se comunicar com os eleitores, 1: Muito pouco: os principais partidos políticos e candidatos raramente usam as mídias sociais durante as campanhas eleitorais para se comunicar com eleitores. 2: Pouco: A maior parte dos partidos e candidatos às vezes usam a mídia social durante as campanhas eleitorais para se comunicar com os eleitores, 3 : Frequentemente: Os principais partidos políticos e candidatos frequentemente usam as mídias sociais durante as campanhas eleitorais para se comunicar com os eleitores.

Disponível em: https://www.v-dem.net/en/analysis/thematic/. Acesso em: 5 de jun. 2020.
} 
Populismo e fake news na era da pós-verdade: comparações entre Estados Unidos, Hungria e Brasil

Quadro 5 - Disseminação de informaçóes falsas através das redes sociais

\begin{tabular}{|l|c|c|c|c|c|c|}
\hline & \multicolumn{2}{|c|}{ Brasil } & \multicolumn{2}{c|}{ EUA } & \multicolumn{2}{c|}{ Hungria } \\
\cline { 2 - 7 } & $\mathbf{2 0 1 4}$ & $\mathbf{2 0 1 8}$ & $\mathbf{2 0 1 2}$ & $\mathbf{2 0 1 6}$ & $\mathbf{2 0 1 4}$ & $\mathbf{2 0 1 8}$ \\
\hline $\begin{array}{l}\text { Disseminação de } \\
\text { informaçōes falsas } \\
\text { pelos partidos }\end{array}$ & 3,11 & 2,03 & 3,08 & 2,99 & 1,49 & 0,77 \\
\hline $\begin{array}{l}\text { Disseminação } \\
\text { (nível doméstico) } \\
\text { de informaçóes } \\
\text { falsas pelo governo }\end{array}$ & 3,49 & 1,63 & 3,59 & 2,94 & 2,22 & 1,58 \\
\hline
\end{tabular}

Fonte: Elaboração própria através de Lührmann et al. (2019).

${ }^{*} 0^{10}$ : Extremamente frequente; 1: Frequente; 2: Parcialmente; 3: Raramente; 4: Nunca.

A escala utilizada vai de 0 (extremamente frequente) a 4 (nunca ou quase nunca) e ranqueia a divulgação de informaçóes falsas por partidos e pelo governo. Primeiramente, cabe ressaltar que tanto no âmbito de governo, quanto no de partidos, houve um aumento na disseminação de fake news nos três países por meio das redes sociais. Enquanto o uso pelos partidos se manteve relativamente estável nos EUA, no Brasil as informações passaram a ser disseminadas com maior frequência e na Hungria com muita frequência. Em nível governamental, todos os países apresentaram quedas mais significativas, com EUA e Brasil passando para uso eventual e a Hungria para uso frequente. Na Hungria, devido a forte censura da mídia, as redes sociais têm respondido a diversos processos por retirar do ar páginas do próprio governo húngaro. Assim, percebe-se, primeiramente, que o fenômeno de difusão de fake news é um elemento que aparece em todos os países estudados e não ocorre apenas com o impulsionamento de partidos, mas também no nível governamental.

Os principais fatores relacionados à produção de fake news na política estão relacionados a fatores econômicos e, também, de ideologia política (ALLCOTT; GENTZKOW, 2017; MCCRIGHT; DUNLAP, 2017). Análises jornalísticas, principalmente a partir do BuzzFeed e do The Guardian, demonstraram que uma

\footnotetext{
${ }_{10}$ 0: Extremamente frequente: Os principais partidos políticos e candidatos/governo divulgam informações falsas sobre todas as questões políticas.; 1: Frequente: os principais partidos políticos e candidatos/ Governo divulgam informações falsas sobre muitas questões políticas.; 2: Parcialmente: Os principais partidos políticos e candidatos/ governo divulgam informações falsas sobre algumas questões políticas fundamentais, mas não outras; 3 : Raramente: os principais partidos políticos e candidatos/governo divulgam informações falsas sobre apenas algumas questões políticas importantes; 4: Nunca, ou quase nunca, os principais partidos políticos e candidatos/governo nunca divulgam informações falsas sobre questões políticas chave.

Disponível em: https://www.v-dem.net/en/analysis/thematic/. Acesso em: 5 de jun. 2020.
} 
porcentagem alta desses sites estava ligada a adolescentes que produziam as notícias falsas na Macedônia por incentivo financeiro, uma vez que as manchetes que viralizam tendem a gerar maior lucro devido aos cliques em anúncios presentes no site (ALLCOTT; GENTZKOW, 2017).

Segundo Vosough, Deb e Aral (2018) que estudaram a disseminação das fake news no Twitter entre 2006 e 2017, nos Estados Unidos, uma notícia falsa tem $70 \%$ mais chance de ser retwitada (compartilhada) do que uma notícia verdadeira e a principal motivação para isso é a novidade, o ineditismo da publicação (VOSOUGHI; DEB; ARAL, 2018). Nesse sentido, a pesquisa também descobriu que os números de compartilhamentos de notícias falsas foram quase os mesmos entre robôs e usuários verídicos - o que indica que apesar da urgência de regular e investigar o uso de robôs nas campanhas eleitorais, também se faz necessário agir em outras frentes contra a desinformação política (BERNARDI, 2019).

A relativização de fatos, baseada em crenças pessoais em um contexto de desconfiança generalizada, está relacionada com o fenômeno da pós-verdade (D’ANCONA, 2018; TRAUMANN, 2018). Além disso, as notícias sobre política nas redes sociais como WhatsApp, Facebook e Twitter têm o poder de alcançar grupos que não são politicamente engajados ou tradicionalmente interessados por política e, portanto, mais suscetíveis a crer em notícias falsas (LAZER et al., 2017). Na Hungria, boa parte da informação falsa partiu do próprio governo, como as campanhas contra a União Europeia e que corroboravam a possibilidade de intervenção russa na região (KREKÓ et al; 2018).

\section{Considerações finais}

Buscamos analisar características da sociedade de cada um dos países estudados, bem como dos líderes populistas que foram eleitos. Embora possam ser resguardadas as diferenças entre as sociedades, os dados de cultura política e opiniáo pública encontrados demonstram, primeiramente, altos índices de desconfiança em relação às instituiçôes políticas tradicionais, sendo os partidos políticos os mais afetados, com taxas de desconfiança entre 60\% e $80 \%$; mostrando, em contraponto, traços autoritários, uma vez que a instituição que conta com mais confiança são as Forças Armadas (ou a Polícia para o caso húngaro), atingindo entre 52 e $74 \%$ de aprovação e contando, curiosamente, com a maior confiança nos Estados Unidos, que não apresentam passado autoritário como os outros dois. Além disso, o que se vê são populaçóes insatisfeitas com os outputs de seus sistemas políticos, não apenas em relação ao desempenho econômico e 
de suas políticas, como de seguridade social, mas também em relação a temas como a corrupção e o próprio modo de governar.

No que tange ao uso de fake news como estratégia política, o Congresso Nacional Brasileiro abriu, em setembro de 2019, um Comitê Conjunto de Inquérito ao Congresso (CPMI) para investigação no âmbito das eleiçôes de 2018. De acordo com o site do Senado Federal (BRASIL, 2019), a investigação incluiu ataques cibernéticos que atentam contra a democracia e o debate público, o uso de perfis falsos para influenciar as eleiçóes de 2018 e práticas de cyberbullying contra usuários e agentes públicos vulneráveis. As notícias falsas também foram objeto de investigação nos Estados Unidos sobre as ligaçóes entre Steve Bannon, ex-consultor da Campanha Trump, e a Cambridge Analytics. A investigação encontrou várias evidências de que Trump estava conspirando com oficiais russos durante as eleiçôes de 2016, mas não o suficiente para o acusar por conspiração (BEAUCHAMP, 2019; BLAKE, 2018). Na Hungria, as notícias falsas são divulgadas pelo próprio governo, pois a maioria dos meios de comunicação é pública. Recentemente, devido ao surto do novo coronavírus, Viktor Orban conseguiu aprovar seu direito de governar por decreto indefinidamente, além de colocar restriçóes ao jornalismo que o governo considera falso e prejudicial à resposta à Covid-19 (NOVAK; KINGSLEY, 2020).

Nesse sentido, no que se refere ao uso de fake news pelo governo, podemos observar que, Donald Trump e Jair Bolsonaro se utilizam de suas redes sociais para disseminar o entendimento que eles têm dos fatos, promovendo forte antagonismo à mídia tradicional e seus opositores políticos, porém, sem promover uma censura direta. No caso da Hungria, onde as principais agências de mídia são governamentais, a limitação da liberdade de imprensa é bem maior e se dá quase como uma açáo do governo.

Quanto aos líderes, os três analisados demonstraram fortes características autoritárias e utilizam as redes sociais como forma de se aproximarem dos eleitores, bem como deslegitimarem o processo democrático e atacarem àqueles com posiçôes opostas, demonstrando características já consagradas de líderes populistas de direita. Em países onde o uso de redes sociais engloba a maioria da população (e para algumas plataformas/países beira a totalidade), a combinação do uso crescente de redes sociais com a disseminação de fake news (somadas ao uso de discurso de ódio) impóem novos desafios e perigos à democracia. Nesse sentido, podemos perceber um autoritarismo mais forte no regime húngaro, uma vez que modificadas as leis principais do país, bem como a estrutura de liberdade de imprensa, torna-se mais claro o caráter iliberal, e, ao nosso ver, fascista de Viktor Orbán. Embora o seu discurso encontre coro com líderes como Bolsonaro 
e Trump, as democracias brasileira e norte-americana vem mostrando sinais um pouco mais fortes de republicanismo - pero no mucho - no Brasil, considerando o recente processo de impeachment e prisão de candidatos da oposição entre 2014 e 2018.

\section{REFERÊNCIAS}

ABRANCHES, S. Polarização radicalizada e ruptura eleitoral. In: ABRANCHES, S. et al. Democracia em risco? 22 ensaios sobre o Brasil de hoje. São Paulo: Companhia das Letras, 2019. p. 9-46.

ALLCOTT, H.; GENTZKOW, M. Social Media and Fake News in the 2016 Election. Journal of Economic Perspectives, Cambridge, MA, v. 31, n. 2, p. 211236, 2017. Disponível em: http://www.nber.org/papers/w23089.pdf. Acesso em: 13 maio 2020

ALMOND, G.; VERBA, S. The Civic Culture. Princeton, EUA: Princeton University Press, 1963.

APPLEBAUM, A. 100 Years Later, Bolshevism Is Back: And We Should Be Worried. The Washington Post [on-line], Washington, 2017. Disponível em: https://www.washingtonpost.com/opinions/global-opinions/bolshevism-then-andnow/2017/11/06/830aecaa-bf41-11e7-959c-fe2b598d8c00_story.html. Acesso em: 11 maio 2020.

ARNAUDO, D. Computational Propaganda in Brazil: Social Bots during Elections. Computational Propaganda Research Project, Oxford, v. 8, p. 1-39, 2017.

ASH, T. G. Europe must stop this disgrace: Viktor Orbán is dismantling democracy. The Guardian [on-line], London, 2019. Disponível em: https://www.theguardian. $\mathrm{com} / \mathrm{commentisfree/2019/jun/20/viktor-orban-democracy-hungary-eu-funding.}$ Acesso em: 8 jul. 2019.

ATKINSONS, S.; SKINNER, G. What worries the world - September 2018. IPSOS [on-line], Paris, 2018. Disponível em: https:/www.ipsos.com/en/what-worries-worldseptember-2018. Acesso em: 30 abr. 2020.

AZEVEDO, D. P. A Comunicação Populista Online: análise das estratégias de comunicação política dos principais candidatos à presidência do Brasil no Facebook durante as eleiçôes de 2018. In: COMPOLÍTICA, 8., Brasília. Anais [...], Brasília, 2019 . 
Populismo e fake news na era da pós-verdade:

comparações entre Estados Unidos, Hungria e Brasil

BAPTISTA, É. A. Corrupçáo e opiniáo pública: O escândalo da Lava Jato no governo Dilma Rousseff. 252f. 2017. Tese (Doutorado em Ciência Política) Programa de Pós-Graduação em Ciência Política, Universidade Federal de Minas Gerais, Belo Horizonte, 2017.

BAQUERO, M. Democracia formal, cultura política informal e capital social no Brasil. Opinião Pública, Campinas, v. 14, n. 2, p. 380-413, 2008.

BAQUERO, M. Formas alternativas de participação política ou naturalizaçáo normativa?: Cultura política e capital social no Brasil. Política \& Sociedade, Florianópolis, n. 5, p. 165-186, 2004.

BAQUERO, M; LINHARES, B. Por que os brasileiros não confiam nos partidos?: Bases para compreender a cultura política (anti)partidária e possíveis saídas. Revista Debates, Porto Alegre, v. 5, n. 1, p. 89-114, 2011.

BAQUERO, M.; RANINCHESKI, S.; CASTRO, H. C. de O. A formação política do Brasil e o processo de democracia inercial. Revista Debates, Porto Alegre, v. 12, n. 1, p. 87-106, 2018.

BEAUCHAMP, Z. The Mueller report's collusion section is much worse than you think. Vox [on-line], 2019. Disponível em: https://www.vox. com/2019/4/18/18484965/mueller-report-trump-no-collusion. Acesso em: 3 jun. 2019 .

BERNARDI, A. J. B. Redes Sociais, Fake News e Eleiçóes: Medidas Para Diminuir a Desinformação nos Pleitos Eleitorais Brasileiros. 121f. 2019. Monografia (Graduação em Filosofia e Ciências Humanas) - Instituto Federal de Filosofia e Ciências Humanas, Universidade Federal do Rio Grande do Sul, Porto Alegre, 2019. Disponível em: http://hdl.handle.net/10183/197602. Acesso em: 4 maio 2020.

BOADLE, A.; STARGARDTER, G. Far-right Bolsonaro rides anti-corruption rage to Brazil presidency. Reuters [on-line], 28 out. 2018. Disponível em: https://www. reuters.com/article/us-brazil-election/far-right-bolsonaro-rides-anti-corruption-rageto-brazil-presidency-idUSKCN1N203K. Acesso em: 31 out. 2018.

BLAKE, A. A new study suggests fake news might have won Donald Trump the 2016 election. The Washington Post [on-line], Washington, 2018. Disponível em: https:// www.washingtonpost.com/news/the-fix/wp/2018/04/03/a-new-study-suggests-fakenews-might-have-won-donald-trump-the-2016-election/. Acesso em: 10 mai. 2020.

BRANCHO-POLANCO, E. How Jair Bolsonaro used 'fake news' to win power. The Conversation [on-line], Boston, January 8, 2019. Disponível em: http:// theconversation.com/how-jair-bolsonaro-used-fake-news-to-win-power-109343. Acesso em: 10 mai. 2020. 
BRASIL. Senado Federal. Comissáo Parlamentar Mista de Inquérito: Fake news. Brasília: Senado Federal, 2019. Disponível em: https://legis.senado.leg.br/comissoes/ comissao?0\&codcol=2292. Acesso em: 05 mar. 2020.

CARNEIRO, F. L. Fake news propagadas por meio digital no Brasil: desafios para a governança e a gestáo pública contemporânea. Belo Horizonte: Fundação João Pinheiro, 2018.

CASTRO, L. N de. Computação e Desinformação: Tecnologias de Detecção de Desinformação Online. In: RAIS, D. (ed.). Fake News: Conexão entre a desinformação e o direito. São Paulo: Thomson Reuters, 2018. p. 61-74.

CHAGAS, V.; SANTOS, J. G. B. A revolução será memetizada: engajamento e ação coletiva nos memes dos debates eleitorais em 2014. E-Compós, Brasília, v. 20, n. 1, 2018 .

COSTA, A. L. V. Corrupção e cultura política em tempos de crise: implicaçóes para a democracia brasileira, Observatório Político, 2018. Disponível em: http://www. observatoriopolitico.pt/wp-content/uploads/2018/12/WP_84_AC.pdf. Acesso em: 10 mai. 2020.

D’ANCONA, M. Pós-verdade: a nova guerra contra os fatos em tempos de fake news. Barueri: Faro Editorial, 2018.

EUROPEAN COMISSION. A multi-dimensional approach to desinformation: Report of the independent High level Group on fake news and online disinformation a multi-dimensional approach to disinformation. Luxembourg: European Union, 2018. Disponível em: https://ec.europa.eu/newsroom/dae/document.cfm?doc id=50271. Acesso em: 3 set. 2019.

FACHIN, P.; MACHADO, R. Eleições 2018: A radicalização da polarização política no Brasil: Algumas análises: Entrevistas especiais. Instituto Humanitas Unisinos [on-line], São Leopoldo, 8 out. 2018. Disponível em: http://www.ihu.unisinos. br/159-noticias/entrevistas/583456-eleicoe... arizacao-politica-no-brasil-algumasanalises-entrevistas-especiais. Acesso em: 31 maio 2019.

GALlEGO, E. S. La bolsonarización de Brasil. Documentos de Trabajo IELAT, Alcalá de Henares, n.121, abr. 2019. Disponível em: https://ielat.com/wp-content/ uploads/2019/03/DT_121_Esther-Solano-Gallego_Web_abril-2019.pdf. Acesso em: 31 maio 2019.

INGLEHART, R. Cultural Evolution: People's Motivations are Changing, and Reshaping the World. New York: Cambridge: Cambridge University Press, 2018. 
INGLEHART, R.; NORRIS, P. Trump, Brexit, and the Rise of Populism: Economic Have-Nots and Cultural Backlash. HKS Working Paper, Cambridge, n. RWP16026, 2016. Disponível em: https://dx.doi.org/10.2139/ssrn.2818659. Acesso em: 23 mar. 2020.

ITUASSU, A. et al. Politics 3.0? De @realDonaldTrump para as eleições de 2018 no Brasil. In: ENCONTRO ANUAL DA COMPÓS, 27., Belo Horizonte - MG. Anais [...], Belo Horizonte: Associação Nacional dos Programas de Pós-Graduação em Comunicação; PUC Minas Gerais, 2018. Disponível em: http://bibliotecadigital. tse.jus.br/xmlui/handle/bdtse/4935. Acesso em: 11 maio 2020.

JUHÁSZ, A. Hungary after the election: Continuing on Orbán's path. Heinrich Böll Stiftung: The Green Political Foundation, Berlin, 2018. Disponível em: https://www. boell.de/en/2018/04/12/hungary-after-election-continuing-orbans-path. Acesso em: 30 abr. 2020.

KAHNEMAN, D. Rápido e Devagar: Duas formas de pensar. Rio de Janeiro: Objetiva, 2012.

KAKUTANI, M. A morte da verdade. Rio de Janeiro: Intrínseca, 2018.

KÖRÖSÉNY, A. Governments and Politics in Hungary. Budapest, Hungary: Central European University Press, 1999.

KREKÓ, P. et al. Beyond Populism: Tribalism in Poland and Hungary. Political Capital [on-line], Budapest, 2018. Disponível em: https://www.politicalcapital.hu/ pc-admin/source/documents/pc_beyond_populism_study_20180731.pdf. Acesso em: 11 jun. 2019.

LAPOP. LAPOP's AmericasBarometer takes the Pulse of Democracy: 2018/19 Regional Report. 2019. Disponível em: https://www.vanderbilt.edu/lapop/ ab2018/2018-19_AmericasBarometer_Regional_Report_10.13.19.pdf. Acesso em: 26 ago. 2020.

LAPOP. The Political Culture of Democracy in the Americas, 2016/17: A Comparative Study of Democracy and Governance: 2016/17 Regional Report. 2017. Disponível em: https://www.vanderbilt.edu/lapop/ab2016/AB2016-17_ Comparative_Report_English_V2_FINAL_090117_W.pdf. Acesso em: 26 ago. 2020 .

LAVALlE, A. G.; HOUTZAGER, P. P.; CASTELLO, G. Democracia, Pluralização da Representação e Sociedade Civil. Lua Nova, São Paulo, n. 67, p. 49-103, 2006.

LAZER, D. et al. Combating Fake News: An Agenda for Research and Action Drawn from presentations by. Shorenstein Center, Cambridge, MS, p. 1-17, May 
2017. Disponível em: https://shorensteincenter.org/wp-content/uploads/2017/05/ Combating-Fake-News-Agenda-for-Research-1.pdf. Acesso em: 17 nov. 2019.

LENGYEL, G.; ILONSZKI, G. Simulated democracy and pseudo- transformational leadership in Hungary. Historical Social Research / Historische Sozialforschung, Cologne, v.37, n. 1 (139), p.107-126, 2012. Disponível em: https://www.jstor.org/ stable/41756453. Acesso em: 17 set. 2019

LEVITSKY, S.; ZIBLATT, D. Como as Democracias Morrem. Rio de Janeiro: Zahar, 2018.

LÜHRMANN, A. et al. V-Dem Annual Democracy Report 2019: Democracy Facing Global Challenges. Gothenburg: V-Dem Institute, University of Gothenburg, 2019.

MAITINO, M. E. Right, unashamed: conformations on Brazil's political right through Jair Bolsonaro’s discourses. Plural: Revista do Programa de Pós-Graduação em Sociologia da USP, São Paulo, v. 25, n.1, p.111-134, 2018.

MARWICK, A.; LEWIS, R. Media Manipulation and Disinformation Online. [s. 1.]: Data \& Society Research Institute, 2017.

MCCRIGHT, A. M.; DUNLAP, R. E. Combatting Misinformation Requires Recognizing Its Types and the Factors That Facilitate Its Spread and Resonance. Journal of Applied Research in Memory and Cognition, Amsterdam, v. 6, n. 4, p. 389-396, 2017. Disponível em: https://linkinghub.elsevier.com/retrieve/pii/ S2211368117302000. Acesso em: 2 jun. 2020.

MEDEIROS, P. Agressão a jornalistas e veículos de comunicação aumenta 54\%, diz relatório; Bolsonaro é responsável por mais da metade. O Globo [on-line], 16 jan. 2020. Disponível em: https://oglobo.globo.com/brasil/agressao-jornalistas-veiculosde-comunicacao-aumenta-em-54-diz-relatorio-bolsonaro-responsavel-por-mais-dametade-1-24195220. Acesso em: 15 fev. 2020.

MULLER, J.-W. The rise and rise of populism. In: BBV; OPENMIND. The Age of Perplexity: Rethinking the World we Knew. [s.l.]: Penguin Random House,

2017. Disponível em: https:/www.bbvaopenmind.com/wp-content/uploads/2018/ 03/BBVA-OpenMind-Jan-Werner-Muller-The-Rise-and-Rise-of-Populism-1.pdf. Acesso em: 5. Jun. 2020.

NEWMANN, N. et al. Digital News Report 2018. Oxford: Reuters Institute, 2019. Disponívelem:https://reutersinstitute.politics.ox.ac.uk/sites/default/files/digital-newsreport-2018.pdf. Acesso em: 25 mai. 2019. 
NORRIS, P.; INGLEHART, R. Cultural Backlash: Trump, Brexit, and Authoritarian Populism. Cambridge: Cambridge University Press, 2019.

\section{NORWEGIAN HELSINKI COMMITTEE. Democracy and human rights at} stake in Hungary: The Viktor Orbán Government's drive for centralisation of power. Oslo, Noruega: NHC, 2013. Disponível em: https://www.civicsolidarity.org/sites/ default/files/democracy_and_human_rights_at_stake_in_hungary.pdf. Acesso em: 15 Out. 2013

NOVAK, B.; KINGSLEY, P. Hungary's Leader Grabbed Powers to Fight the Virus: Some Fear Other Motives. The New York Times [on-line], New York, 2020. Disponível em: https://www.nytimes.com/2020/04/05/world/europe/victor-orbancoronavirus.html?searchResultPosition=1. Acesso em: 8 abr. 2020.

OATES, S.; MOE, W. W. Donald Trump and the "Oxygen of Publicity": Branding, Social Media, and Mass Media in the 2016 Presidential Primary Elections. SSRN Electronic Journal, [s. 1.], 2016. Disponível em: https://dx.doi.org/10.2139/ ssrn.2830195. Acesso em: 26 ago. 2020.

OWEN, D. The New Media's Role in Politics. OpenMind BBVA, 2017. Disponível em: https://www.bbvaopenmind.com/en/articles/the-new-media-s-role-in-politics/. Acesso em: 26 ago. 2020.

OXFORD LANGUAGES. Post Truth. In: OXFORD LANGUAGES. Word of The Year 2016. Oxford: Oxford University Press, 2016. Disponível em: https://languages. oup.com/word-of-the-year/2016/\#:-:text=After\%20much\%20discussion $\% 2 \mathrm{C} \% 20$ debate\%2C\%20and,to\%20emotion\%20and\%20personal\%20belief'. Acesso em: 26 ago. 2020.

PINHEIRO-MACHADO, R.; SCALCO, L. M. The Bolsonaro Effect. Jacobin, New York, 2018. Disponível em: https://jacobinmag.com/2018/10/brazil-electionbolsonaro-corruption-security-pt. Acesso em: 26 ago. 2020.

RENWICK, A. Electoral System Change in Europe since 1945. West European Politics, Abingdon, v.34, n.3, p.456-477, 2011. Disponível em: <http://www. electoralsystemchanges.eu/Files/media/MEDIA_213/FILE/Hungary_summary.pdf/> Acesso em: 22 mai. 2020.

ROBERTS, K. M. Crises of Representation and Populist Challenges to Liberal Democracy. Chinese Political Science Review, Heidelberg, v.4, p. 188-199, 2019.

RUEDIGER, M. Desinformaçáo na era digital: amplificaçóes e panorama. Rio de Janeiro: FGV DAPP, 2018. 
SANTANA, P. H. B. Midiatização da Política em Tempos de Redes Sociais Digitais: A Suposta Campanha Precoce de Jair Bolsonaro. In: SEMINÁRIO INTERNACIONAL DE PESQUISAS EM MIDIATIZAÇÃO E PROCESSOS SOCIAIS, 2., 2017, São Leopoldo. Anais [...], São Leopoldo: UNISINOS, 2017. Disponível em: http:// www.midiaticom.org/anais/index.php/seminario-midiatizacao-artigos/article/ download/293/287. Acesso em: 26 ago. 2020.

SARGENTINI, J. Relatório sobre uma proposta solicitando ao Conselho que, nos termos do artigo $7 .^{\circ}$, n. $^{\circ} 1$, do Tratado da Uniáo Europeia, verifique a existência de um risco manifesto de violaçáo grave pela Hungria dos valores em que a Uniáo assenta. [s.l.]: Parlamento Europeu; Comissão das Liberdades Cívicas, da Justiça e dos Assuntos Internos, 2018.

SHU, K. et al. Fake News Detection on Social Media: A Data Mining Perspective. Ithaca: Cornell University, 2017. Disponível em: http://arxiv.org/abs/1708.01967. Acesso em: 11 set. 2019.

SIERAKOWSKI, S. How Eastern European Populism Is Different. Project Syndicate, January 31, 2018. Disponível em: https://www.project-syndicate.org/commentary/ populism-stronger-in-eastern-europe-by-slawomir-sierakowski-2018-01. Acesso em: 22 out. 2018.

SILVERMAN, C. This Analysis Shows How Viral Fake Election News Stories Outperformed Real News On Facebook. BuzzFeedNews, 2016. Disponível em: https://www.buzzfeednews.com/article/craigsilverman/viral-fake-election-newsoutperformed-real-news-on-facebook. Acesso em: 31 maio. 2019.

STANLEY, J. Como funciona o fascismo: a política do "Nós" e "Eles". Porto Alegre: L\&PM Editores, 2018.

SUGARS, S. From fake news to enemy of the people: An anatomy of Trump's tweets. Comitee to Protect Journalists [on-line]. 2019. Disponível em: https:/cpj. org/blog/2019/01/trump-twitter-press-fake-news-enemy-people.php. Acesso em: 28 maio. 2019.

THE 2016 ELECTION Fact Checker. The Washington Post, Washington, 2016. Disponível em: https:/www.washingtonpost.com/graphics/politics/2016-election/ fact-checker/. Acesso em: 31 mai. 2019.

TRAUMANN, T. Como a indústria de notícias falsas dominou a eleição da França. Época, n. 4, p. 1-5, 2018. Seção Mundo. 
VEGETTI, F. Political polarization in Hungary. The ANNALS of the American Academy of Political and Social Science, Thousand Oaks, CA, v.681, n.1, p.78-96, 2018.

VOSOUGHI, S.; DEB, R.; ARAL, S. The Spread of True and False News Online. Science, Washington, v.359, n.6380, p.1146-1151, 2018.

Recebido em 01 de maio de 2020.

Aprovado em 08 de junho de 2020. 